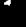

\title{
DOSIMETRY MEASUREMENTS EXTERNAL TO A 10 KILOLITER LIQUID-AIR VESSEL CONTAINING A D-T NEUTRON SOURCE
}

D. J. Tripler

E. Goldberg

W. E. Farley

October 10, 1977

$$
\text { 每 }
$$$$
\text { . }
$$

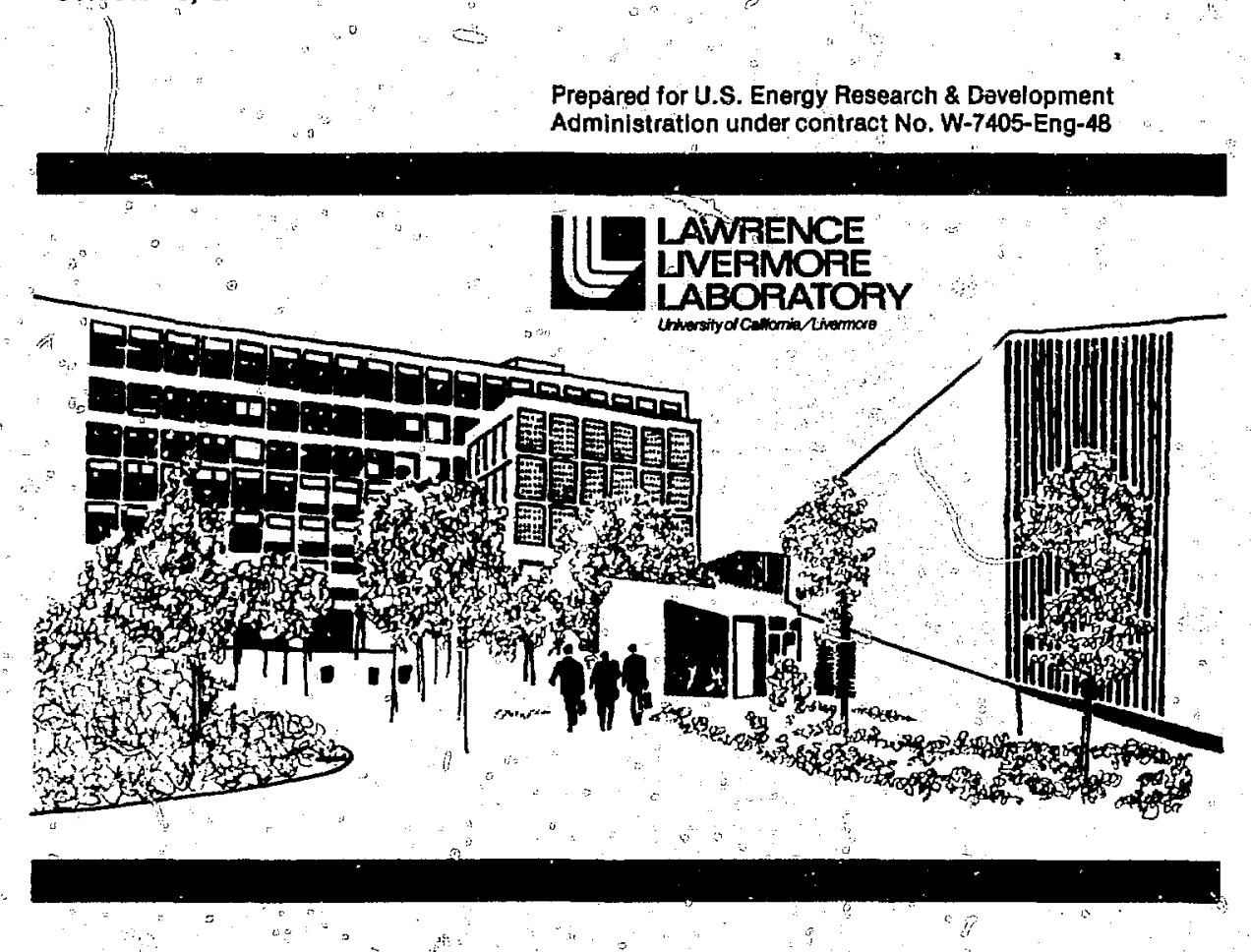




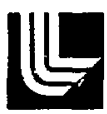

\title{
LAWRENCE LMEAMXRE LABOAATOAY
}

\author{
University of Caltomia/Livermore,Cellomia/94550
}

UCRL-52334

\section{DOSIMETRY MEASUREMENTS EXTERNAL TO A 10 KILOLITER LIQUID-AIR VESSEL CONTAINING A D-T NEUTRON SOURCE}

\author{
D. J. Tripler \\ E. Goldberg \\ W. E. Farley
}

Ms. date: October 10, 1977

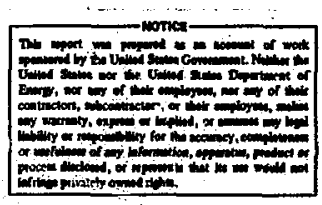




\section{CONTENTS}

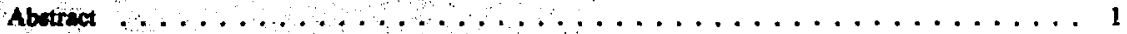

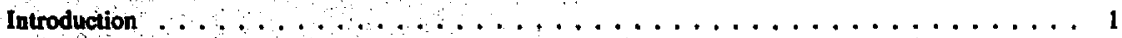

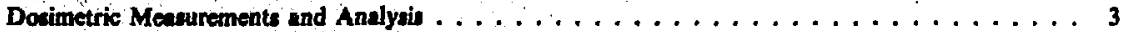

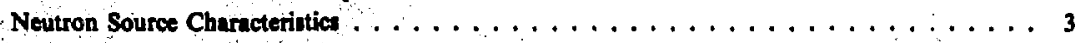

Titure Equivalent Ion Chamber $\ldots \ldots \ldots \ldots \ldots \ldots$

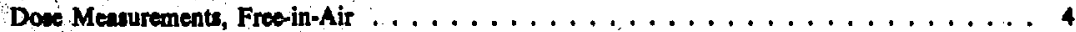

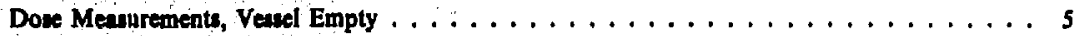

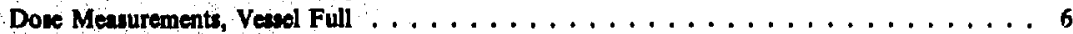

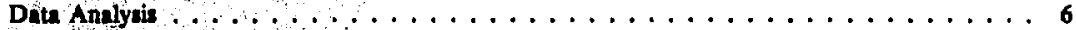

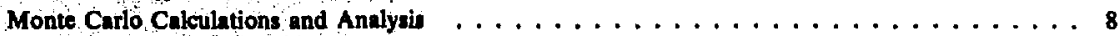

Unhielded Detector $\ldots \ldots \ldots \ldots \ldots \ldots \ldots \ldots \ldots \ldots \ldots$

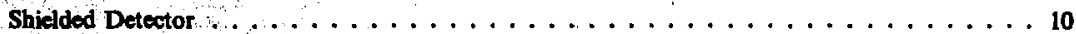

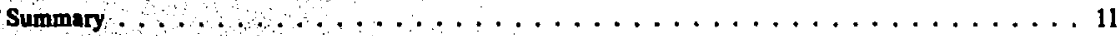

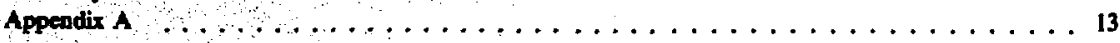

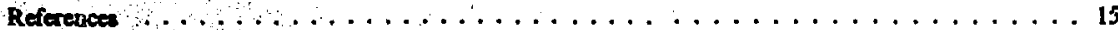

(n) 


\title{
DOSIMETRY MEASUREMENTS EXTERNAL TO A 10 KILOLITER LIQUID-AIR VESSEL CONTAINING A D-T NEUTRON SOURCE
}

\begin{abstract}
To determine the radiation attenuation characteristics of liquid air $\left(109 \mathrm{~g} / \mathrm{cm}^{2}\right.$ thick) for $14 \mathrm{MeV}$ neutrons from a central D-T source in a $10 \mathrm{~kL}$ vessel, radiation dose measurements were made using a large tissue-equivalent ion chamber external to the vessel. The shielding characteristics of steel spherical shells were also investigated. Experimental results were analyzed and compared with TARTNP Monte Carlo code calculations. Degradation of the ion chamber's response to high-energy neutrons was established and incorporated into the analysis. The dose attenuation factor for the unshielded detector was measured to be 0.073 , compared with the calculated value of 0.081 . The shielded detector signals were reduced only modestly; with a 10-cm-thick shell, the signal from the filled vessel dropped twofold.
\end{abstract}

\section{INTRODUCTION}

From April 1-8, 1976, experiments were conducted at the Insulated Core Transformer (ICT) accelorator facility at Lawrence Livermore Laboratory to determine the radiation attenuation of liquid air. The apparatus used in these experiments is shown in Fig. I. It is a large (10-kl) spherical double-walled vessel containing liquid air 4.2 to $129.3 \mathrm{~cm}$ from its center. At its center there is a D-T neutron source. Neutrons pass threugh $\sim 109$ $\mathrm{g} / \mathrm{cm}^{2}$ of the liquid air before leaving the vessel. In 1975, this apparatus had been used in experiments with liquid nitrogen. ${ }^{1}$ As for these ea:lier experiments, the primary objective of this study was to measure time-of-flight to infer the emergent neutron and ganma spectra.

Neutron dosimetry measurements were made external to the vessel with a large $\left(\sim 90-\mathrm{cm}^{3}\right)$ tissueequivalent (TE) ion chamber (Fig. 2). For these measurements, integrated signals were used, whereas the pulsed sphere time-of-flight experiments discriminated against any steady-state contribution. Consequently, if processes such as capture-gamma ray production are important, dose values inferred from the ilynamic spectral measure. ments could fall below the neutron doses measured by the ion chamber.

To assess the effect of steel as a shield material, measurements were made with the ion chamber sur- rounded by spherical steel sheils 5.0 and $10.0 \mathrm{~cm}$ thick.

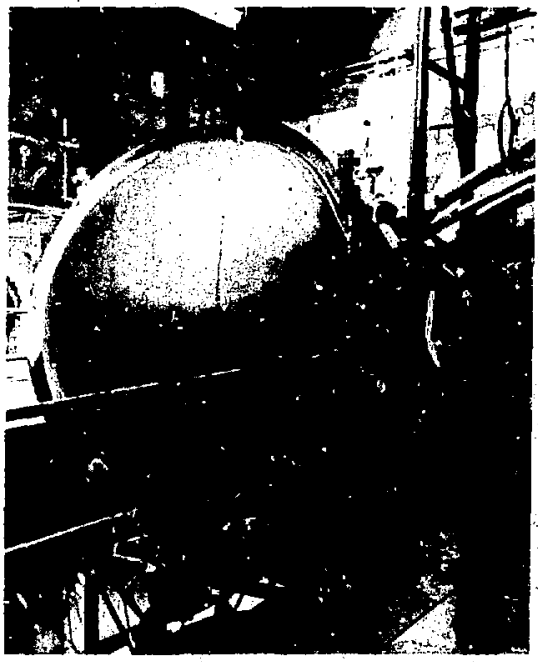

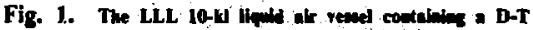
nevirow source used for indiation attemation sturites. 


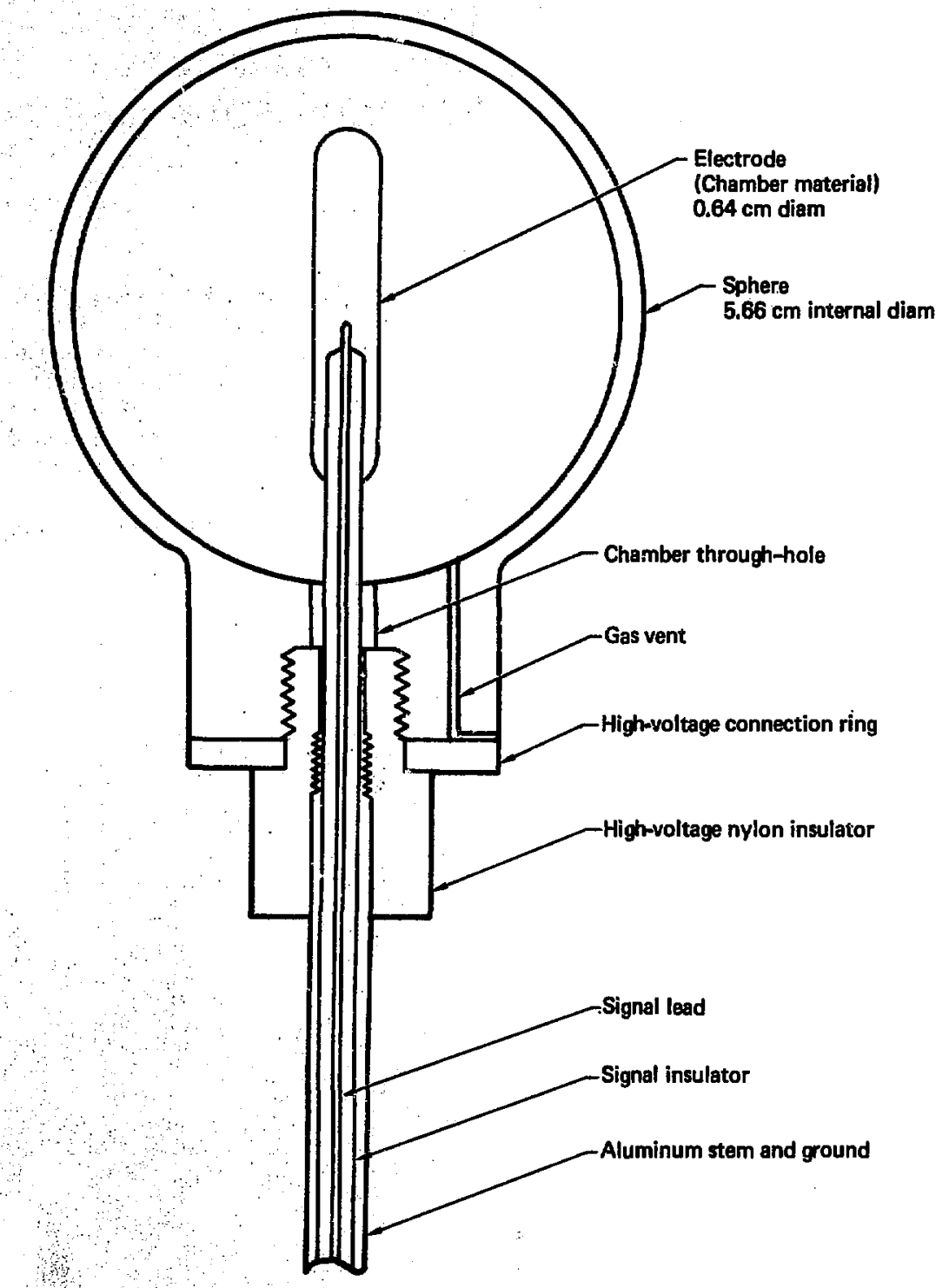

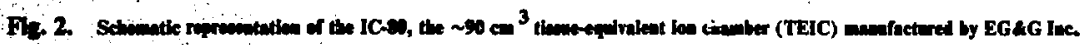




\section{DOSIMETRIC MEASUREMENTS AND ANALYSIS}

\section{Neutron Source Characteristic?}

A low-mass D-T source was constructed for use with the large liquid air vessel. The characteristics of this uni. are described by Wong. ${ }^{2}$ The neutrons are produced by the pulsing $400 \mathrm{keV}$ deuteron beam that strikes a tritiated disc at the end of the assembly. Neutron production was monitored by counting the associated alpha particles [i.e., $\mathrm{T}(\mathrm{d}, \mathrm{n}) \alpha \mathrm{d}$ at a well-defined incremental solid angle in the rear direction.

A single tritium target was used during these tests. The geometry of the alpha detector was not considered in determining the conversion factor; rather, an NE213 proton recoil counter of known sensitivity and with an absolute accuracy of $\pm 7 \%^{3}$ was used as an absolute flux monitor. From April 18,1976 , the conversion factor using this method was $2.21 \times 10^{6} \mathrm{n} / \mathrm{sr} \cdot \alpha$ count. The factor corresponds to neutrons emitted in the forward direction at an angle of $26^{\circ}$ with respect to the deuteron beam line. A $6 \%$ correction is included to account for air attenuation over a $9.54 \mathrm{~m}$ path to the recoil counter. The neutrons are emitted not quite isotropically or isoergically with a beam of $400 \mathrm{keV}$ deuterons. The forward direction energy is $\sim 15.1 \mathrm{MeV}$, and the intensity is $\sim 6 \%$ above the average.

The source operated at $\sim 10^{9} \mathrm{n} / \mathrm{s}$, which was wellsuited to our time-of-flight measurements. At a distance of $\sim 2 \mathrm{~m}$, however, this implies a dose $\sim 500$ $\mathrm{mrad} / \mathrm{h}$ for the unfilled vessel, and one order of magnitude less for the experiment with the vessel filled with liquid air. Carcful attention to electronic details was necessary, so we removed the electrometer from the radiation field and avoided patch panels to maintain drift currents in the $10^{-15} \mathrm{~A}$ range.

The experimental pit was a cube $6.1 \mathrm{~m}$ on a side and the source was $5.1 \mathrm{~m}$ from the forward wall. The pit's concrete walls were $1.9 \mathrm{~m}$ thick, and the ceiling's wooden beams were at least I ra thick.

\section{Tissue-Equivalent Ion Chamber}

Our tissue-equivalent ion chamber illustrated in Fig. 2, is a spherical plastic shell mounted on a long aluminum stem with a central electrode. As designed, it is insensitive to orientation with respect to the source. Earlier calibrations with gamma rays and the high-intensity ICT source had indicated a sensitivity of the chamber to orientation. This has since been found to be due to the electrofineter acting alone as an ion chamber. In this study, the electrometer was placed outside the experimental pit and connected by a single double-shielded cable to the ion chamber. For all measurements, the ion chamber was aligned with its stem radially outward from the source.

The plastic walls, designated Shonka A-1504, have a hydrogen content close to that of living tissue. The chamber was used throughout with tissue-equivalent gas flowing through at a rate of $\sim 5 \mathrm{~cm}^{3} / \mathrm{min}$. The compostions of Shonka A-15n plastic and TE gas in wt\% are ${ }^{5}$ : Shonka A-150, Ki (9.9), $\mathrm{C}(77.1), \mathrm{N}(4.4), \mathrm{O}(5.0)$, other elements (3.6); TE gas, $\mathrm{CH}_{4}$ (64.51), $\mathrm{CO}_{2}$ (32.31), $\mathrm{N}_{2}$ (3.16), irspurities (0.02).

The chamber voltage on the sphere was maintained at $\pm 300 \mathrm{~V}$. When activated by a gamma source, the sensitivity varied by less than $1 \%$ for voltages between 200 and $500 \mathrm{~V}$. Drift values were taken fo: each polarity and corrections were made using the appropriate drift values.

With TE gas flowing through the chamber, the manufacturer's calibration for ${ }^{60} \mathrm{Co}$ gamma rays was $3.33 \times 10^{7} \mathrm{rad} / \mathrm{C}\left(760 \mathrm{~mm} \mathrm{Hg}, 22^{\circ} \mathrm{C}\right)$. Our checks agreed within $3 \%$ of this value. Placement of a $\sim 0.15$-cm-thick plastic sheet in front of the detector made no measurable change in its response to gamma rays.

With no radiation source present, the electrometer used with the ion chamber produced currents of 0 to $4 \times 10^{-15} \mathrm{~A}$, depending on the hamber's polarity. Within the target pit, the reading rose a few femtoamperes, which implied a background level of $\sim 0.3$ to $0.4 \mathrm{mR} / \mathrm{h}$, consistent with radiation survey meter readings. The radiation source was undoubtedly due to the activation of surrounding walls and structures in the pit. Attainment of these low readings was essential to the cxperiment since the signals recorded with the tank filled with liquid air and with the ion chamber shielded were not greatly in excess of background signals.

Temperatures and pressures were recorded regularly to correct the chamber gas density. Reduction of the chamber gas density reduced the ionization for a given radiation field. We took drift measurements frequently, and corrected all integrated currents according to the time elapsed from the initial (zeroing) to the final reading; with regard to chamber polarity. 


\section{Dose Messurements, Free-In-Air}

Readings were taken with the chamber at \pm 300 V. At times, we capped the ion chamber with a plastic cup with a thickness equal to that of the chamber wall. The cap did not attenuate the signal, implying a zero correction for the chamber wall for $15 \mathrm{MeV}$ neutrons. A typical run with cap off is shown in Table 1. From Table 1, we find the instrument's current to be $\sim 8 \times 10^{-13} \mathrm{~A}$.

Figure 3 illustrates the results of the free-in-air measurements. Measurements wete taken with the ion chamber surrounded by mild steel spherical shells with a $10.1-\mathrm{cm}$ inner radius. The shells were either $5 \mathrm{~cm}$ or $10 \mathrm{~cm}$ thick. The data is plotted as a function of $R^{2}$ rather than $R$ to reveal any trend indicative of a constant background radiation $B$ (i.e., dose $\left(S / R^{2}\right)+B$, where $S$ is the source strength). Additional data shown in Fig. 3 corresponds to measurements with the empty ressel in place.
The free-in-air (unshielded) findings extrapolate to a value of $Q \cdot R^{2} / \Delta \alpha=3.58 \times 10^{-10} \mathrm{C} \cdot \mathrm{cm}^{2} / \Delta \alpha$ for zero spacing. The collected charge $Q$ has been corrected for room background and detector drift,

Table 1. Characteristics of a typical neutron dose messurament

Distance from source to ion chember center, $\mathbf{R}$

$103.4 \mathrm{~cm}$

Number of monitor a counts $\Delta a \quad 17,886$

Voltuge on chamber

$+300 \mathrm{~V}$

Integrated chine $\mathbf{Q}$

Time interval of ton $\Delta t$

$0.641 \mathrm{nC}$

Beckgound current - st

$13 \mathrm{~min}$

Temperature

$0.047 \mathrm{nC}$

$16.2^{\circ} \mathrm{C}$

Proune

$748.7 \mathrm{~mm} \mathrm{~Hz}$

Corrected chiure $Q_{c}\left(22^{\circ} \mathrm{C}, 760 \mathrm{~mm} \mathrm{Hg}\right) 0.633 \mathrm{nC}$

Collected chare over distance per aph $Q_{c} \cdot R^{2} / \Delta a$

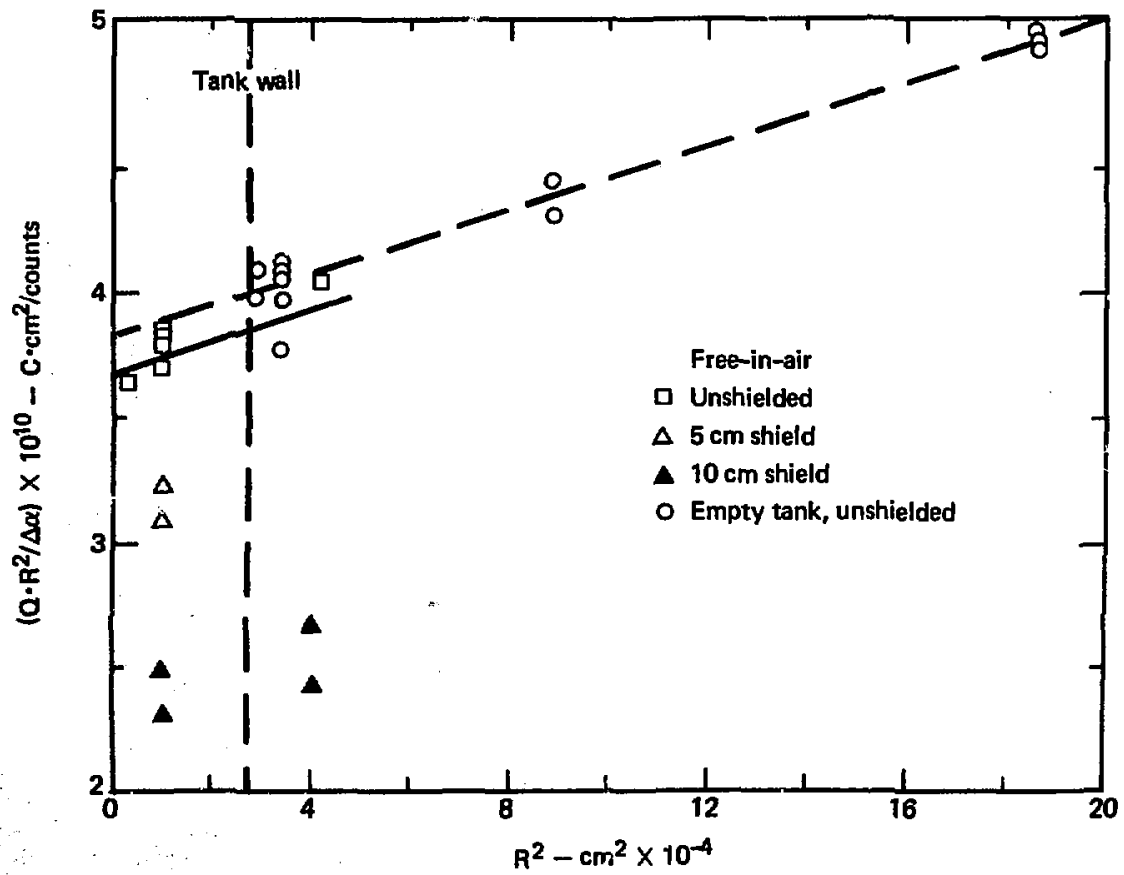

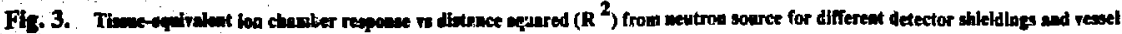
frecilair. Menurenets then at 760 an Hs and $22^{\circ} \mathrm{C}$. 
and is adjusted to $22^{\circ} \mathrm{C}$ and $760 \mathrm{~mm} \mathrm{Hg}$. At a $1-\mathrm{m}$ spacing between source and detector, the room return correction is approximately $\sim 2 \%$.

When the 5-cm thick steel shield was in place, the signal was reduced to $\sim 0.84$ of the unshicided value, while the $10-\mathrm{cm}$ thick shield reduced the signal to $\sim 0.64$ of the unshielded value.

Since the associated particle recoil counter is calibrated, the value for $Q \cdot R^{2} / \Delta \alpha$ may be translated to a more meaningful form:

$$
\text { fluence } \begin{aligned}
\Phi & =\frac{2.21 \times 10^{6}(n / S r \Delta \alpha)}{R^{2}} \times \Delta \alpha, \\
Q & =\frac{3.68 \times 10^{-10}(\mathrm{C} / \mathrm{Sr} \Delta a)}{R^{2}} \times \Delta \alpha,
\end{aligned}
$$$$
\frac{Q \text { (Coulombs) }}{\Phi \cdot \mathrm{n} / \mathrm{cm}^{2}}=1.67 \times 10^{-16}\left(\mathrm{C} \cdot \mathrm{cm}^{2} / \mathrm{n}\right)
$$

$$
\left(22^{\circ} \mathrm{C}, 760 \mathrm{~mm} \mathrm{Hg}\right)
$$

The latter value will be used later in the analysis of the experiment.

One year earlier, we had determined $Q / \Phi$ to be $1.825 \times 10^{-16} \mathrm{C} \cdot \mathrm{cm}^{2} / \mathrm{n}$. In calculating this value, we incorporated an air-attenuation correction factor of $6 \%$. The present value is 0.915 of the earlier value, suggesting a possible deterioration of detector response to $15 \mathrm{MeV}$ neutrons. On the other hand, the ion chamber : $:$ ponse to ${ }^{60} \mathrm{Co}$ gamma radiation appeared unchanged over one year.

\section{Dose Measurements, Vessel Empty}

The liquid air vessel we used is described by Sidhu. ${ }^{1}$ For the dosimetry experiments, the critical dimensions of the spherical vessel we used are the radial dimensions of the four walls; these are listed in Table 2. With the fluid removed, the vessel walls interpose $\sim 1 \mathrm{~cm}$ of metal between source and detertor. The removal of neutrons from the high-energy peak of the spectrum estimated from pulsed spheres is $\sim 12 \%,{ }^{6}$ However, the dose attenuation is expected to be more modest since the scattered neutrons and the secondary gamma rays arising from inelastic scattering contribute significantly to the dose.

Figure 3 shows the detector's response with the vessel in place. The vessel here enhances the dose by $4 \%$. On the other hand, experiments one year earlier showed an $\sim 5 \%$ attenuation in dose. Generally, fluctuations in the data are in this range, and we conclude tha $i$ the empty tank has no effect within an uncertainty range of $\sim \pm 4 \%$ in dose.

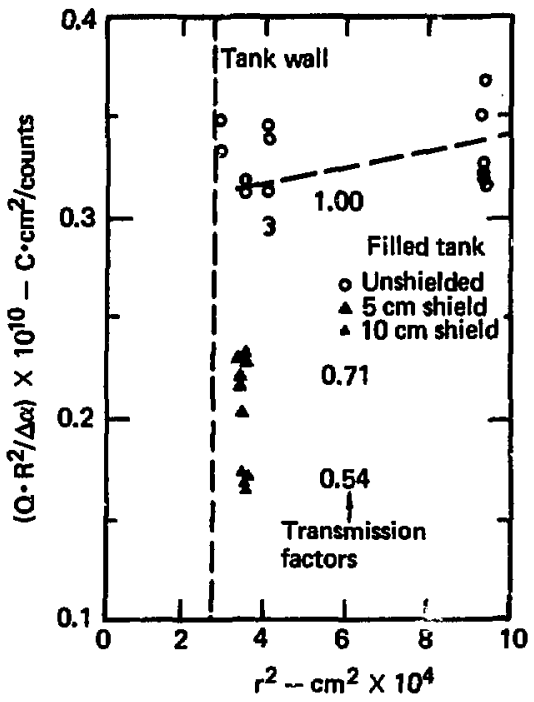

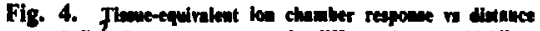

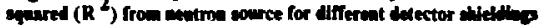

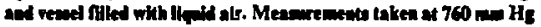

\begin{tabular}{|c|c|c|c|c|c|}
\hline W\|l & $\begin{array}{l}\text { Indde redius } \\
\mathbf{R}_{\mathbf{i}} \text {, } \\
\mathrm{cm}\end{array}$ & $\begin{array}{l}\text { Outulde rodiun } \\
\mathbf{R}_{\mathrm{o}} \\
\mathrm{cm}\end{array}$ & $\begin{array}{l}\text { Difference } \\
\Delta R \text {, } \\
\mathrm{cm}\end{array}$ & $\begin{array}{l}\text { Dearity } \\
\rho, \\
g / \mathrm{cm}^{3}\end{array}$ & Maberial \\
\hline $\mathbf{I}$ & 3.09 & 3.18 & 0.081 & 7.92 & Stuinlew ated \# 30 \\
\hline in & 4.09 & 4.18 & 0.081 & 7.92 & Ssrinleas thed \#304 \\
\hline III & 129.31 & 129.84 & 0.533 & 8.72 & Everdur (Cu alloy) \\
\hline IV & 164.86 & 165.28 & 0.453 & 7.85 & Mild real \\
\hline
\end{tabular}
and $22^{\circ} \mathrm{C}$

Tsble 2. Dimensions of liquid air spharical vesal 


\section{Dose Measurements, Vesse' r}

From April I through 6 1976, the iron vessel was Filled with liquid air. Normally, air contains 0.93 molar \% Argon and 0.03 molar $\% \mathrm{CO}_{2}$, neither of which was present in the liquid we sth:-d. Our liquid air composition was $21 \pm 1$ molar $\%$ oxygen and $79 \pm 1$ molar \% nitrogen. The liquid density was measured as $0.869 \mathrm{~g} / \mathrm{cm}^{3}$, compared :o the standard value for liquid air (with Ar) of $0.874 \mathrm{~g} / \mathrm{cm}^{3}$. The $\Delta \rho r$ for the liquid is therefore $103.7 \mathrm{~g} / \mathrm{cm}^{2}$.

Figure 4 illustrates the detector retoonsi vs distance squared $\left(\mathbf{R}^{2}\right)$ from the neutron siurce. Here, the spread of data points is greater than those in Fig. 3 because when the liquid air was inserted, the signals were decreased by over one order of magnitude. Instrument drift and background corrections were 1 +o $3 \%$ for the data shown in Fig. 4. The dispersion of data at common positions is $\sim 7 \%$.

Figure $S$ summarizes the findings with all data normalized to the freefield findings. If the ion chamber was tissue-equivalent for all neutron energies, this normalization would illustrate the extent of shielding caused by the liquid air. The apparent isquid air attenuation factor is $\sim 0.082$ for $109 \mathrm{~g} / \mathrm{cm}^{2}$ of liquid air, assuming the metal shells of the vessel to have a net zero effect.

With liquid air in the vessel, the ion chamber was also operated with the shields. Runs were madie with the detector successively operated inside the spherical 5- and $10-\mathrm{cm}$ thick iron shields. The results, shown in Figs. 4 and 5 indicate dose transmission factors of 0.71 and 0.54 for the two shields, respectively.

The shielded detector measurements are televant to the estimation of radiation shielding afforded by military tanks. If the detector readings accurately represent the tissue-equivalent dose, we may assign a dose attenuation mean-free-path of $\sim 15 \mathrm{~cm}$ to a tank exposed to nuclear radiation similar to that emanating from the vessel filled with liquid air. A 2in. steel wall would therefore transmit $71 \%$ of the free-field radiation dose.

\section{Data Analysis}

The ion chamber we used is designed to exhibit tissue-equivalent behavior to all forms of radiation. The $1-\mathrm{cm}^{3}$ tissue-equivalent ion chamber regularly used at the ICT facility has been extensively studied and found to exhibit a tissue-equivalent response at $15 \mathrm{MeV}$ neutron energy. ${ }^{7} \mathrm{~A}$ uniform response to neutron energy is especially desirable so that one may take ratios of measurements with the liquid air filled vissel to those measurements free-in-air (and thereby sidestep considerations of absolute detector efficiency, which would cancel out).

We carefully examined the large ion chamber's absoluie response to $15 \mathrm{MeV}$ neutrons and dr'ermined the kerma per unit fluence, as shown in Appendix $A$. We find that at a neutron energy $E_{n}$ of 15 $\mathrm{MeV}$, the ion chamber's response is 0.79 of the desired tissue-equivalent value.

One year earlier, the value of $Q / \Phi$ was $\sim 9 \%$ higher, which \&uggests that the detector deteriorated in retponse to $15 \mathrm{MeV}$ neutrons.

We explored independent means to judge whether the chamber response was below design expectations. Megsurements were made using ${ }^{60} \mathrm{Co}$ sources and a ${ }^{252} \mathrm{Cf}$ spontaneous fission source, with the large jon chamber used here and the l-cc ion chamber, the subject of the study in Ref. 7. Recently, the two chambers were compared at the ICT facility using $15 \mathrm{MeV}$ neutrons. In Table 3 are listed the ratios of charge $Q$ collected for a comiun integrated radiation flux. Corrections are made for the greater wall thickness of the smaller ion chamber (i.c., 0.51 vs $0.23 \mathrm{~cm}$ ).

The relative response of the large ion chamber to $15 \mathrm{MeV}$ neutrons is approximately .82 of that for ${ }^{60} \mathrm{Co}$ or ${ }^{252} \mathrm{Cf}$ radiation, which is in close agreement with the value derived in Appendix A from the Bragg-Gray relation.

In this study, the major correction stems from the fact that our ion chamiser was not tissue equivalent when used at $15 \mathrm{MeV}$ neutron energy. Since we have made a comparison between measurements with the vissel filled to that free-in-air, the latter data is subject to the full correction for the chamber's lack of tissue-equivalency. To unfold the correct attenuation factors would require prior knowledge of the

Table 3. Detector response ratio a(jC-80)/a(IC-17)

\begin{tabular}{llll}
$\begin{array}{c}\text { Redintion } \\
\text { cource }\end{array}$ & $\begin{array}{c}\text { Filling } \\
\text { ges }\end{array}$ & Ratio & $\begin{array}{c}\text { Cocrectod } \\
\text { ratio }\end{array}$ \\
\hline${ }^{60} \mathrm{Co}(\gamma)$ & Alr & $89.6^{*}$ & 88.7 \\
${ }^{60} \mathrm{Co}(\gamma)$ & TE & $87.9^{\circ}$ & 87.0 \\
${ }^{60} \mathrm{Co}(\gamma)$ & TE & 91.1 & 90.0 \\
${ }^{252} \mathrm{Cf}(n, \gamma)$ & TE & 93.6 & 90.0 \\
$15 \mathrm{MoV}(n)$ & TE & 72.3 & 71.0 \\
$15 \mathrm{MeV}(n)$ & Air & 75.7 & 74.0 \\
\hline
\end{tabular}

Menufacturer"s ${ }^{60} \mathrm{C}$, celibration values. 


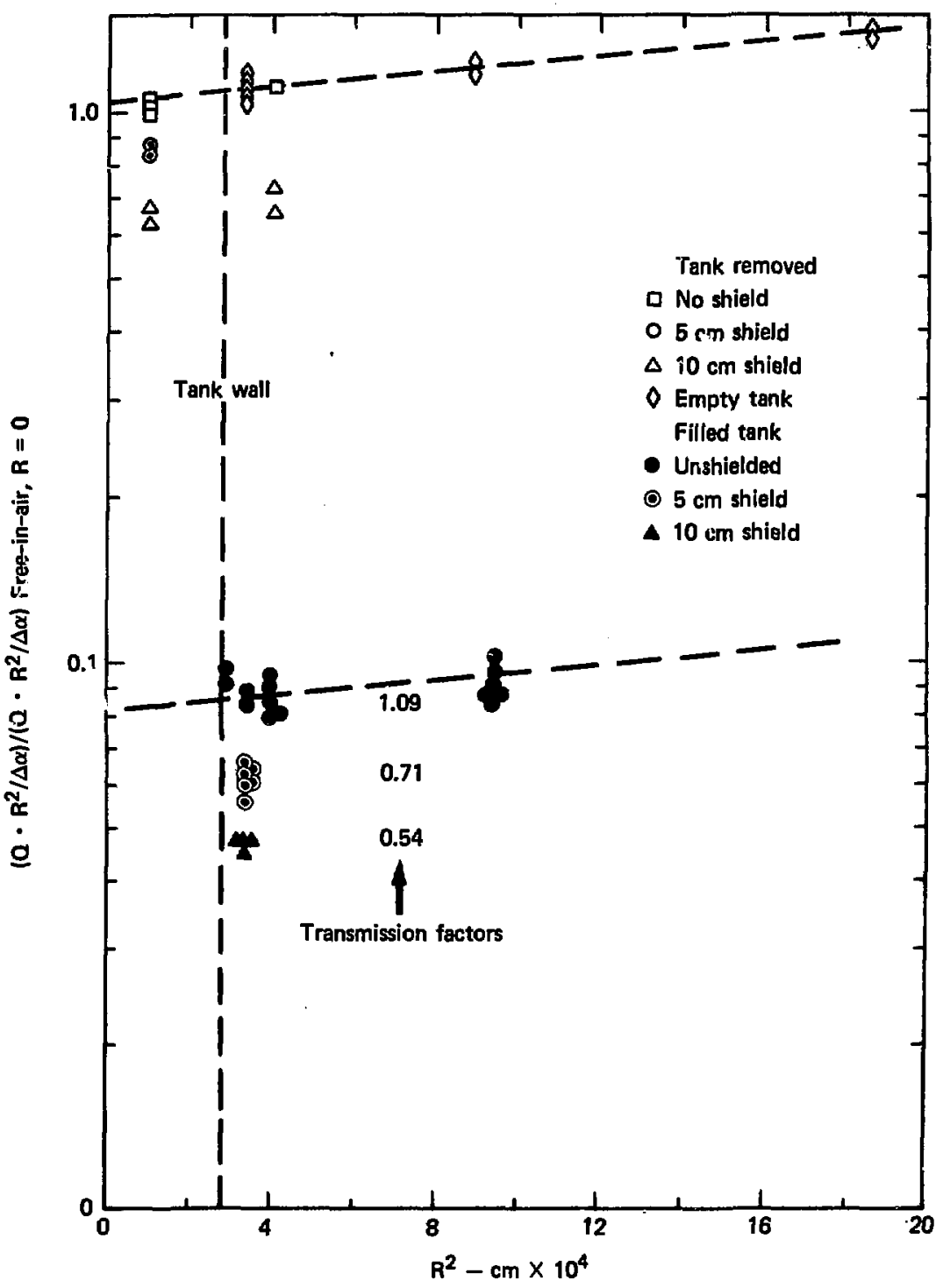

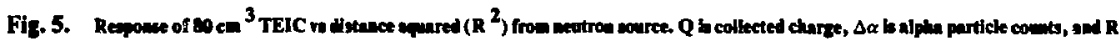
is cibtance from somree to betector. 
spectral nature of the radiation. We have therefore taken advantage of our Monte Carlo calculations to fold the detector response function into the appropriate calculations to permit a direct experimental comparison and to avoid tedious unfolding process. This procedure treated below then allows us to generate a dose-attenuation factor that we would find experimentally with a fully tissueequivalent ion chamber.

Since the maximum correction upon measurement is encountered at $15 \mathrm{MeV}$ neutron energy, we may anticipate that the largest adjustment to the dose-attenuation factor will be $\sim 20 \%$. In all cases, the correction wi:I decrease the apparent dose attrenuation factor. Where the spectrum falling on the detector has a weak high neutron energy component (i.e., $E_{n}>10 \mathrm{MeV}$ ) for both of the configurations being compared, the net correction should be $<<$ $20 \%$.

To summarize, the free-in-air readings are simply interpreted as suppressed by a factor of .79 to .82 with respect to full tissue-equivalency. In free-field conditions, the uncorrected experimental doseattenuation factors for the $5-$ and $10-\mathrm{cm}$ thick steel shells were 0.84 and 0.64 , respectively. The corresponding factors for the filled vessel were 0.71 and $\mathbf{0 . 5 4}$, respectively.

\section{MONTE CARLO CALCULATIONS AND ANALYSIS}

As of June 22 1976, the TARTNP Monte Carlo neutron/photon transport code ${ }^{8}$ with the current Evaluated Neutron Data Library ${ }^{9}$ was used for calculations for both the uns'ielded and shielded ion chamber measurements previously discussed. Since the code geometry input for these two cases varied considerably and the data from them is not directly comparable, each will be presented separately.

\section{Unshicided Detectors}

\section{Newtron Source and Geowetry}

Here, data were derived using the neutron source described earlier. This source, which closely matches the characteristics of the ICT source, is distinguishod by a $\sim 6 \%$ above average neutron energy in the forward direction, i.e., $15.1 \mathrm{MeV}$.

Where included in the Monte Carlo calculations, the liquid air container, the ICT target pit, and the concrete pit walls were described as a series of concentric spherical shells with the dimensions taken from Table 1 .

\section{Free-I-Air}

To permit direct comparison of calculations to experimental data, it was necessary to first determine the calculated kerma factor $K$ per unit fluence $\Phi$ at the origin (see Appendix A). This removed effects such as air attenuation. This factor may be derived directly from the nuclear cross-sections and rexiction energies incorporated in the code. We found excellent agreement between the two procedures.
TARTNP code calculations were run with a geometry that included neutron source, air, and target pit walls. The walls were represented as spherical, and the detectors as thin spherical ca-s of $30^{\circ}$ half-angles in the forward direction. The coses are plotted in Fig. 6. The units given for $D \cdot R^{2}$ are radiation dose absorbed (rad) $\cdot \mathrm{cm}^{2} /$ source neutron $\mathrm{n}$.

Extrapolation of these curves to the origin gave a value of $\sim 6.07 \times 10^{-10} \mathrm{rad} \cdot \mathrm{cm}^{2} / \mathrm{n}$, which we used to normalize all TARTNP data for the unshielded detector calculations. Corrected for sourcs anisotropy, this value corresponds to $7.19 \times 10^{-7}$ $\operatorname{erg} \cdot \mathrm{cm} / \mathrm{g} \cdot \mathrm{n}$, or about $1.3 \%$ higher than the value

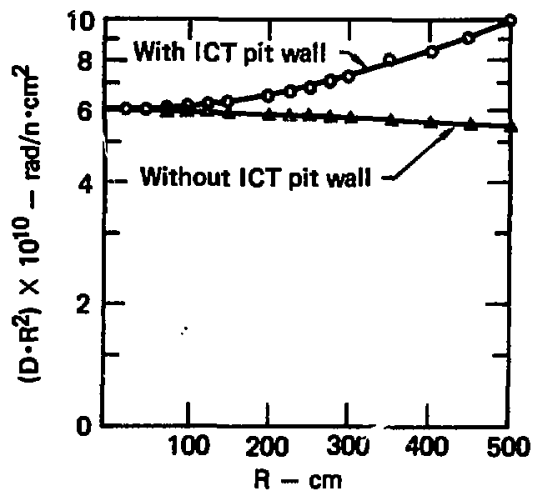

Fig. 6. TARTNP cole calcolations of radintion doce abaorbed with and witoon ICT pit wall w distence $R$ from newtron sonres. 
calculated for A-150 plastic. This discrepancy is likely due to statistical error.

Extrapolation of the curves to the ICT pit wall ( $R$ $=514.68 \mathrm{~cm}$ ) revealed a dose enhancement by the wall $\sim 1.7$ times a simple $1 / R^{2}$ dependence at that radius. The decrease of $D \cdot R^{2}$ from a horizontal line for the free-in-air measurement without the $;$ it wall was due to detector and air attenuation.

\section{Empty Vessel}

In Fig. 7, we illustrate normalized values of TARTNP and mean experimestal doses external to the emply vassel as a function of distance from source to ion thamber center. For comparison, we also plotted normalized TARTNP calculated doses for the free-in-air case. A comparison of the values obtained from our experiments to our calculations showed excellent agreement in normalized dose determinations relatively close :r the vessel surface (170 to $300 \mathrm{~cm}$ from the source): the TARTNP values were within $1 \%$ of our mean experimental values. Although we suspected a degradation in the detector's response to high energy neutrons, the comparison of normalized values is not significantly affected by this since the presence of the empty vessel does not appreciably alter the neutron spectrum. Careful examination of Fig. 8 reveals a slight dose enhancement very close to the vessel $(<200$ $\mathrm{cm}$ ). This is due to scattering of the emergent radiation by the vessel walls. Generally, the calculated effect of the vessel's presence was $<1 \%$ increase in dose over free-field calculations.

A considerable spread of $\sim 7.7 \%$ between measured and calculaie $\rfloor$ values at approximately $430 \mathrm{~cm}$ distance is probably attributable to an increased dose from room return as a result of describing the room walls as a spherical shell in the Monte Carlo calculations.

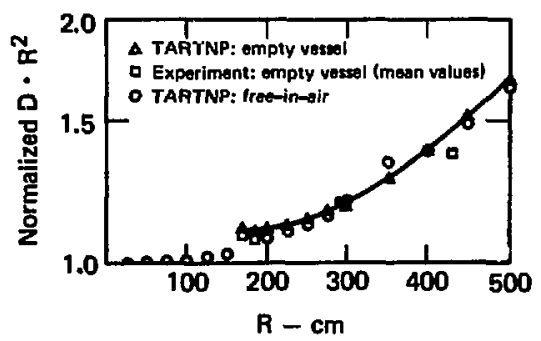

Fig. 7. Conparian of TARTNP code calculations with experimentel dats of alworbed dose vo distance $R$ frow nestron source.
Vessel with Liquid Air

The effect of the liquid air (density $\rho=0.869$ $\mathrm{g} / \mathrm{cm}^{3}$ ) is illustrated for normalized TARTNPcalculated dosts for the empty and filled vessel in Fig. 8. At 200 to $30 \mathrm{~cm}$ from the source, where vessel and roon wall effects are minimized, the calcuiated average dose attenuation factor was 0.0814 , which is remarkably close to our experimental value of 0.082 .

A valid comparison between calcrlated and experimental values requires a correction of the latter, since from Table 2, the ion chamber's response is degraded for neutrons with energies above a fission spectrum. In Appendix $A$, an $\sim 20 \%$ reduction in response was inferred for neutrons with energies of $\sim 15 \mathrm{MeV}$. We did not know the exact nature of the degradation or the energy region over which it applies, so we assumed a $20 \%$ reduction in response for the following two extreme cases:

1. Degraded response of $80 \%$ for $E_{n}>12 \mathrm{MeV}$. About $25 \%$ of the total dose external to the filled vessel results from such neutrons.

2. Degraded response of $80 \%$ for $E_{n} \geqslant 2 \mathrm{MeV}$. About $50 \%$ of the total dose external to the filled vessel results from such neutrons.

Rather than attempting an unfolding process, we used data taken from Monte Carlo calculatious in conjunction with the two detector response functions given above to generate attenuation factors that could be compared directly to experimentai values.

In applying this folding-in procedure, we generated the following corrected values of measured dose attenuation with the vessel filled:

For case $1,0.0714\left(E_{n}>12 \mathrm{MeV}\right)$.

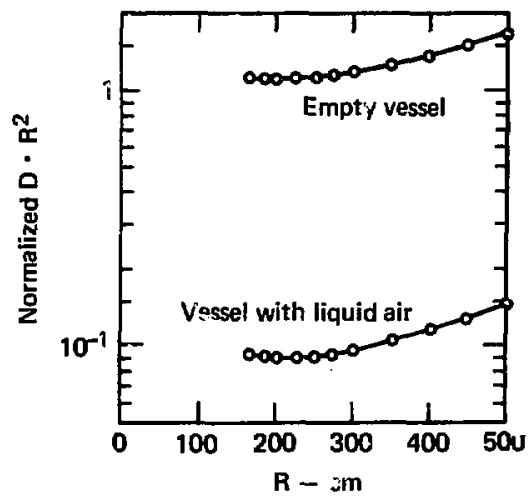

Fig. R. TARTNP code calculations comparing absorbed dose for empty and filled ressel vs distance $R$ trom neutron source. 
For case $2,0.0750\left(E_{n}>2 \mathrm{MeV}\right)$, with a degraded response of 0.8 employed. A reasonable estimate of the corrected experimental dose attenuation should be between these two extrenes; the mean value of 0.073 with an experimental uncertainty of $\pm 15 \%$ seems appropriate to us. The TARTNP-calculated dose attenuation of 0.0814 falls within this $\pm 15 \%$ uncertainty, the experimental mean value being $\sim 10 \%$ lower than the Monte Carlo value. Even this disagreement is not unreasonable since it evolves over some 2.5 doseattenuation, mean-free paths. A $4 \%$ increase in the attenuation cross sections in the calculations would produce agreement. The discrepancy falls within the experimental uncertainty.

\section{Platon Dase}

In addition to total (neutron + photon) dose, TARTNP calculations provided information on photon dose alone. The photons contributing to the total dose were created in the vessel walls, room walls, room air, liquid air, and detectors. The results of the Monte Carlo calculations are summarized here.

Free find caleulationa Photons created in the room air and "detectors" contributed from 0.1 to $0.5 \%$ of the total dose. The photon dose contribution due to the presence of the ICT pit walls varied from $\sim 0.1 \%$ near the source to $\sim 10 \%$ near the walls:

Enpty resel calctalations. An empty vessel increased the photon total dose an additional 2 to $3 \%$.

Veacel with liquid air culculations. Photons contributed about $24 \%$ to the total dose, of which only $\sim 1 \%$ was due to room return.

\section{Shielded Detector}

Compared with the dimensions of the ICT target pit and the liquid air vessel, the relatively small size of the steel shields and ion chamber made it impractical to merely add these features to the geometry used for the Monte Carlo calculations for the unshielded detector. Such an approach would have required an inordinate amount of computer time to obtain reasonable statistical data. The technique described below provided rapid and reliable results and is particularly justified because of the spherical geometry of the detector and shields.

\section{Newtree and Gamen Sowrcel}

Since the dose of radiation through the liquid air vewel had already been calculated for the unshielded detector, we saved considerable coniputer time by using available data. Radiation incident on the shields included neutrons emerging from the vessel or thuse scattered by system components such as the walls, and secondary gamma rays created throughout the system.

The neutron and gamma sources used for most of these calculations were generated from the forwarddirected spectra, external and close to the outer surface of the vessel filled vith liquid air. The sources were described as collimated beams fully irradiating the shields.

\section{Geometry}

The tissue-equivalent ion chamber and steel shields were described as concentric spherical shells. Baseline unshielded calculations were run for this geometry using only the A-150 plastic/TE gas ion chamber. For shielded calculations, we first added the inner $5-\mathrm{cm}$ thick steel shell $\left(R_{i}=10 \mathrm{~cm}\right)$ and then the outer $5-\mathrm{cm}$ thick steel shell.

\section{Free-in-Air}

The TARTNP calculations for the free-in-air condition were made using a $15-\mathrm{MeV}$ neutron source. The experimental and calculated shield transmission factors are summarized in Table 4. The corrected experimental values were derived using the same general procedures as described earlier when corrections were made for unshielded ion chamber measurements,

The corrected experimental measurements of dose transmission for the $80-\mathrm{cm}^{3}$ TEIC are approximately 6 and 15\% lower than the Monte Carlo calculated values for the 5 and $10 \mathrm{~cm}$ shields, respectively. We checked for potential causes of these differences. Iron removal (nonelastic) cross sections used in the TARTNP calculations were checked against experimental results. ${ }^{6}$ For this Monte Carlo calculation, a $14 \mathrm{MeV}$ neutron isotropic point source was placed inside a $10-\mathrm{cm}$ thick iron shell 6 $=7.87 \mathrm{~g} / \mathrm{cm}^{3}$ ). Results compared in Table 5 show no significant differences; here, the discrepancy is within experimental uncertainty.

Table 4. Tranunistion factors: freo-in-air geometry

\begin{tabular}{lll} 
Experimentit messurements & $5 \mathrm{~cm}$ stecl & $10 \mathrm{~cm} s \mathrm{sted}$ \\
\hline $90-\mathrm{cm}^{3}$ TEIC (corrected) & $0.78 \pm 0.09$ & $0.57 \pm 0.11$ \\
$1-\mathrm{cm}^{3}$, TEIC $^{10}$ & 0.76 & 4.53 \\
TARTNP calculations & 0.83 & 0.67
\end{tabular}


Table 5. Comparison of experimental dats and TARTNP calculations for iron removal cross sections per unit mass

$\frac{\Sigma / p\left(\mathrm{~cm}^{2} / \mathrm{g}\right)}{\text { Experiment } \quad \text { TARTNP }}$

\begin{tabular}{|c|c|c|}
\hline $\begin{array}{l}\text { Foe remowal from hiph- } \\
\text { energy penk }\end{array}$ & 0.0153 & 0.0158 \\
\hline $\begin{array}{l}\text { For neutron kinetic energy } \\
\text { bove } 2 \mathrm{MeV}\end{array}$ & 0.0099 & 0.0106 \\
\hline
\end{tabular}

Table 6. Tranemistion factors extornal to liquid sirfilled reanl

\begin{tabular}{lcc} 
Experiments measuremonts & $5 \mathrm{~cm}$ stoel & $10 \mathrm{~cm} \mathrm{sued}$ \\
\hline $90-\mathrm{cm}^{3}$ TEIC (correctod) & $0.70 \pm 0.02$ & $0.52 \pm 0.03$
\end{tabular}

TARTNP celculations

Neutrons and rocondary genmes created in shield 0.846 0.681

Secondary gammass incident on shield

Total

0.72

$\mathbf{0 . 5 3}$

\section{Vessel with Liquid Air}

Summarized in Table 6 are the experimental and calculated transmission factors for the steel shields external to the vessel filled with liquid air. The corrected experimental values were derived as previously described.

Here, the agreement between corrected experimental values and code calculations is close, the corrected measurements falling 2 to $3 \%$ below the results calculated by TARTNP. This is a very significant comparison since the dose results from radiation transported through both the liquid air and the steel shields. The detector's degraded response to high-energy neutrons was not a significant factor in this case, since the high-energy neutron peak was strongly attenuated by the liquid air.

\section{Comparison to Time-of-Flight Experiments}

At the time of our study, Farley ${ }^{11}$ measured the neutron and gamma spectra emerging from the liquid air vessel using time-of-flight techniques. Their findings were also compared to TARTNP coric results. The dose from neutrons was inferred by folding appropriate kerma factors into both calculated and measured leakage spectra; the experimental and calculated gamma-ray, pulse-height spectra were used to directly derive the gamma dose. The experimentally derived total dose was found to be $5 \%$ greater than the calculations predicted. By contrast, in this study the experimental dose was $10 \%$ less than that calculated by TARTNP. Similarly, a reliability of $15 \%$ was attributed to the dose calculations by Farley's group. The difference in total dose determinations falls within the uncertainties we cite.

\section{SUMMARY}

- A large $\left(\sim 90 \mathrm{~cm}^{3}\right)$ tissue-equivalent ion chamber was used at the ICT facility to make radiation dose measurements external to a 10-kl spherical vessel filled with liquid air. From a low-mass D-T source, neutrons were generated at the vessel's center.

- This ion chamber responded at $\sim 80 \%$ of its expected level when exposed to $15 \mathrm{MeV}$ neutrons. The reduced performance was determined by the Bragg-Gray relation and by comparison to the response of a $1.0 \mathrm{~cm}^{3}$ ion chamber, which had been independently shown to behave as tissue-equivalent.

- The $\sim 90 \mathrm{~cm}^{3}$ ion chamber appeared to be tissue-equivalent in the field of a ${ }^{252} \mathrm{Cf}$ source.

- When filled, the spherical vessel contained $p \Delta r=109 \mathrm{~g} / \mathrm{cm}^{2}$ of liquid air $\left(\sim 21\right.$ molar $\% \mathrm{O}_{2}, 79$ molar $\% \mathrm{~N}_{2}$ ). The observed dose when corrected for deviation from tissue equivalence was reduced to $0.073 \pm 0.011$ of the free-field dose by the filled tank.

- In free-field geometry, spherical iron shells of 5.0 and $10.0 \mathrm{~cm}$ thickness and $10.0 \mathrm{~cm}$ inner radius, reduced the dose due to $1.5 \mathrm{MeV}$ neutrons to $0.78 \pm$ 0.09 and $0.57 \pm 0.11$ of the unshielded dose, respectively. These results ware corrected for detector deviation from tissue equivalence.

- For the radiation field external to the liquidair-filled vessel, the 5 - and $10-\mathrm{cm}$ thick shields reduced the dose to $0.70 \pm 0.02$ and $0.52 \pm 0.03$ of the unshielded dese, respectively. Here, the incorporated detector response corrections were mociest. 
- The Monte Carlo calculations confirmed experimental findings of the shielding properties for liquid air and steel shells, agreement being within the experimental uncertainties of the measurements.
- The code calculations of dose attenuation factors were higher than the experimental results by as much as $\sim 10 \%$. The results of our measurements and calculations are summarized in Table 7.

Trble 7. Sumnury of revilts

Corrected experinenter velues
Monte Eivio Experiment/ celculntions

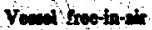

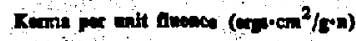

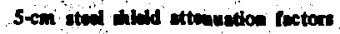

10-cin and hild ithoution fectors

Vond and with riould at

Lquid sis attranation fectors

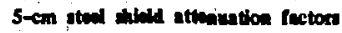

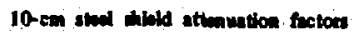

$5.58 \times 10^{-7}$

$0.78 \pm 0.09$

$0.57 \pm 0.11$

$7.19 \times 10^{-7}$

0.78

0.83

0.94

0.67

0.85

$0.073 \pm 0.011$

0.081

0.90

$0.70 \pm 0.02$

0.72

0.97

$0.52 \pm 0.03$

0.53 


\section{APPENDIX A}

\section{Derivation of Kerma Per Unit Fluence for Large Ion Chaniber}

In an ion chamber, the energy absorbed in the gas (per gram of gas), when exposed to gamma rays, according to the Bragg-Gray relation is as follows:

$$
D_{r}^{\operatorname{six}} \times \frac{Q_{r} W_{e}}{M_{g a x}}
$$

where $Q_{\boldsymbol{\gamma}}$ is the collected charge and $W_{e}$ is the energy absorbed per ion pair. The energy deposited in the gas is due mainly to primary ions formed in the chamber walls, and the energy per gram deposited in the walls reflects the stopping power of the primary ions in the two regions:

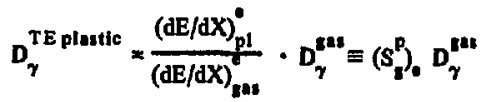

$$
\begin{aligned}
& =\left(\mathrm{S}_{\mathrm{s}}^{\mathrm{P}}\right) \frac{\mathrm{Q}_{\mathrm{\gamma}} \mathrm{W}_{\mathrm{s}}}{\mathrm{M}_{\text {gas }}} \text {. }
\end{aligned}
$$

When the detector is calibrated in a known field, the results are given in units such as coulombs/roentgen $(C / R)$, where the $R$ field refers to the free-field reading with air as reference:

$$
D_{\gamma}^{\text {sir }} \text { (rads) }=0.869 R \text {. }
$$

In such a field, the energy deposited per gram of plastic would vary as its energy absorption coefficient:

$$
D_{\gamma}^{T E}=\frac{(\mu / \rho)_{\mathrm{TE}}}{(\mu / \rho)_{\text {air }}} \cdot D_{\gamma}^{\text {Iir }}=\frac{(\mu / \rho)_{\mathrm{TE}}}{(\mu / \rho)_{\text {air }}} \cdot 0.869 R .
$$

Substituting, we find that

$$
\left(\mathrm{S}_{\mathrm{e}}^{\mathrm{P}}\right)_{\mathrm{e}} \frac{\mathrm{Q}_{\gamma} \mathrm{W}_{0}}{\mathrm{M}_{\mathrm{gas}}}=\frac{(\mu / \rho)_{\mathrm{TE}}}{(\mu / \rho)_{\text {air }}} \cdot 0.869 \cdot R .
$$

The chamber volume is then

$$
\mathrm{V}=\frac{\mathrm{M}}{\rho}=\frac{\left(\mathrm{S}_{\mathrm{L}}^{\mathrm{p}}\right)_{\mathrm{e}} \mathrm{Q}_{\gamma} \mathrm{W}_{\mathrm{o}}}{\frac{(\mu / \rho)_{\mathrm{TE}}}{(\mu / \rho)_{\text {air }}} \cdot 0.869 \cdot \rho_{\mathrm{air}} \cdot R}
$$

The values for $S_{e}$ and $W_{e}$, taken from $R e f .7$, for air in the chamber are

$$
\begin{aligned}
\left(S_{s}^{p}\right)_{e} & =1.140, \\
W_{e} & =33.7 \mathrm{eV} / \text { ion pair },
\end{aligned}
$$


and

$$
\frac{(\mu / p)_{\mathrm{TE}}}{(\mu / \rho)_{\mathrm{dr}}}=1.102
$$

The manufacturer's calibration gives

$$
Q / R=2.88 \times 10^{-2} \mathrm{C} / \mathrm{R}
$$

at standard temperature and pressure. Therefore, we find a chamber volume of $89.4 \mathrm{~cm}^{3}$.

The walls are $0.23 \mathrm{~cm}$ thick so self attenuation of the gamma tays leads to an $\sim 1 \%$ correction, raising the volume to $90.25 \mathrm{~cm}^{3}$.

When the instrument with tisue-equivalent gas filling is ${ }^{60} \mathrm{Co}$-calibrated and parameters for that filling are taken from. Ref. 7, a chamber volume of $87.0 \mathrm{~cm}^{3}$ is found. An average volume of $88.6 \mathrm{~cm}^{3}$ coripares reasonably well to $89.2 \mathrm{~cm}^{3}$, determined by comperison of the response of a calibrated $1 \mathrm{~cm}^{3}$ ion chamber. The average volume of $88.9 \mathrm{~cm}^{3}$ will be used. With the chamber filled with tissue equivalent (TE) gas of density $1.046 \mathrm{~g} / 1$ at $25^{\circ} \mathrm{C}$, our calibration temperature and pressure of $22^{\circ} \mathrm{C}$ and $760 \mathrm{~mm} \mathrm{Hg}$, we calculate a gas miss of $0.0939 \mathrm{~s}$.

In Ref. 7, the correction dealing ivith the difference between gas and solid in heavy ion stopping-power is discussed. For proton, the stoppins power of TE gas is taken to be 1.06 times that for TE solid; for electrons, the ratio is 1.03. The net effect is to reduce the $K / \Phi$ value by $3 \%$.

Finally, the flux depreasion duc to self-sbsorption by the detector must be estimated. The chamber wall is $0.229 \mathrm{~cm}$ thick, with a density of $1.12 \mathrm{~g} / \mathrm{cm}^{3} .12$ The equilibrium cap had a thickness of $0.15 \mathrm{~cm}$ teflon and $0.10 \mathrm{~cm}$ plastic. The areal densities were $0.37 \mathrm{~g} / \mathrm{cm}^{2}$ plastic and $0.31 \mathrm{~g} / \mathrm{cm}^{2} \mathrm{CF}_{2}$. Reasonably, we assume that neutrons do not multiply satter in the chamber, so that the removal cross sections cited by Logan and Komoto ${ }^{6}$ are appropriate. They calculated

$$
0.37 \times 0.0778+0.31 \times 0.0292=0.038
$$

Therefore, in $\sim 4 \%$ attenuation is appropriate. On the other hind, in a bulky target such as that studied by Maruyama and Bouts, ${ }^{13}$ a relaxation length of $24 \mathrm{~cm}$ in polyethylene would suggest a $\sim 2 \%$ attenuation. We will assume the mean of these two, and apply a correction of 1.03 .

Equation (A-1) is now used to evaluate the kerma per unit fluence. The dose in the plastic may be equated to the kerma-i.e., energy deposited by heavy charged particles, with no contribution from the primary or secondery gamma rays within the field: This expression also holds in a neutron field. Dividing both sides by the fluence $\Phi$ and including the corrections we have discussed, we derive:

$$
(\mathrm{K} / \Phi)_{\text {all }}=\frac{(\mathrm{Q} / \phi)\left(\mathrm{C} \cdot \mathrm{cm}^{2} / \mathrm{n}\right) \cdot 31.4(\mathrm{eV} / \mathrm{ion} \mathrm{p} \text { irr }) \cdot 1.601 \times 10^{-12} \mathrm{erg} / \mathrm{eV} \cdot 1.03}{1.601 \times 10^{-19} \mathrm{C} / \mathrm{esu} \cdot \mathrm{M}_{\mathrm{gLs}} \cdot 1.03}
$$

The value for $Q / \Phi$ was found earlier to be $1.67 \times 10^{-16} \mathrm{C} \cdot \mathrm{cm}^{2} / \mathrm{n}\left(22^{\circ} \mathrm{C}, 760 \mathrm{~mm} \mathrm{Hg}\right)$, and the TE gas mass was 00398 .

We therefore calculate:

$$
(\mathrm{K} / \text { (\$) })_{\mathrm{wil}}=5.58 \times 10^{-9} \mathrm{nd} \mathrm{cm}^{2} / \mathrm{n}
$$

in A-150 plastic at $22^{\circ} \mathrm{C}$ and $760 \mathrm{~mm} \mathrm{Hg}$.

The value derived from basic cros-sections is $7.07 \times 10^{-9} \mathrm{rad} \cdot \mathrm{cm}^{2} / \mathrm{n}$. The detector response at $\mathrm{E}_{\mathrm{n}}=15$ MeV appears then to be 0.79 times the tissue-equivalent value. 


\section{REFERENCES}

1. G. S. Sidhu, W. E. Fariey, L. F. Hansen, T. Komoto B. Pohl, and C. Wong, Nucl. Sci. and Eng. 63, 48 (1977).

2. C. Wong, Livermore Pulsed Sphere Program: Program Summary Through July, 1971. Lawrence Livermore Laboratory, Rept. UCRL-51144 (1972).

3. C. Wong, Lawrence Livermore Laboratory, Private communication (1977).

4. J. B. Smathers, Med. Phys. 1, 74 (1977).

5. H. H. Rossi and G. Failla, Nucleonics 14, 32 (1956).

6. C. M. Logan and T. T. Komoto, Observed Penetration of 14-MeV Neutrons in Various Materials, Lawrence Livermore Laboratory, Rept. UCRL-51663 (1974).

7. H. H. Barschall and E. Goldberg, Med. Phys, 4, 141 (1977).

8. E. F. Plechaty and J. R. Kimlinger, TARTNP: A Coupled Neutron-Photon Monte Carlo Transport Code, Lawrence Livermore Laboratory, Rept. UCRL-50400, Vol. 14 (1976).

9. E. F. Plechaty, Tabular and Graphical Presentation of 175 Neutron Group. Constants Derived from the $L L L$ Evaluated Neutron Data Library (ENDL). Lawrence Livermore Laboratory, Rept. UCRL-50400, Vol. 16 (1976).

10. E. Goldberg, Lawrence Livermore Laboratory, Private communication (1976).

1i. W. E. Farley, "Neutron- and Gamma-Ray Transport Experiments in Liquid Air" in Energy and Technology Review, Lawrence Livermore Laboratory Rept. UCRL-52000-76-7 (1976).

12 W. M. Quam, EG\&G, San Ramon, CA, Private communciation (1976).

13. T. Maruyama and C. J. Bouts, Phys. Med. Biol. 17, 420 (1972). 